\section{A Comprehensive Approach to Adrenal Incidentalomas}

\begin{abstract}
Improvements in abdominal imaging techniques have increased the detection of clinically inapparent adrenal masses, or incidentalomas (AI), the appropriate diagnosis and management of which have become a common clinical problem for health care professionals. Once an adrenal mass has been detected, the clinician needs to address two questions: 1) is the tumor hormonally active? and 2) is there any chance of the mass being malignant? The majority of Al is nonhypersecretory cortical adenomas, but an endocrine evaluation can lead to the identification of subtle hormone excess. An overnight lowdose dexamethasone suppression test, fractionated urinary or plasma metanephrine assay and, in hypertensive patients, establishing the upright plasma aldosterone/plasma renin activity ratio are recommended as preliminary screening steps. Masses greater than $4 \mathrm{~cm}$ are at greater risk of malignancy. Morphological imaging features may be helpful in the distinction between benign and malignant forms. Fine-needle aspiration biopsy is an important tool in the evaluation of oncological patients to establish any metastatic disease. Adrenalectomy is indicated by evidence of a functional adrenal mass, or a suspected malignant form. We advocate adrenalectomy of subtle hypercortisolism, especially in the presence of hypertension, obesity, diabetes or osteoporosis potentially aggravated by glucocorticoid excess. A close followup is needed, particularly in the first year after diagnosis. (Arq Bras Endocrinol Metab 2004;48/5:583-591)
\end{abstract}

Keywords: Adrenal incidentaloma; Benign adenoma; Carcinoma

\section{RESUMO}

\section{Uma Abordagem Abrangente do Incidentaloma Adrenal.}

$O$ aperfeiçoamento das técnicas de imagem abdominal tem aumentado a detecção de massas adrenais clinicamente não aparentes, ou incidentalomas (IA), cujo diagnóstico e manuseio apropriados têm se tornado um problema clínico comum para os profissionais da saúde. Uma vez detectada uma massa adrenal, o clínico é obrigado a formular duas questōes: 1) o tumor é hormonalmente ativo? e 2) existe alguma possibilidade de a massa ser maligna?. A maioria dos IA são adenomas corticais não hipersecretores, mas uma avaliação endócrina pode resultar na identificação de um excesso hormonal sutil. Como passos preliminares de screening são recomendados um teste de supressão overnight com doses baixas de dexametasona, a dosagem de metanefrinas em urina fracionada ou no plasma e, em pacientes hipertensos, estabelecer a relação da aldosterona plasmática/atividade plasmática de renina na posição ortostática. Massas maiores que $4 \mathrm{~cm}$ têm risco maior de malignidade. Achados morfológicos de imagem podem ser valiosos na distinção entre formas benignas e malignas. A biópsia de aspiração com agulha fina é um procedimento importante na avaliação de pacientes oncológicos para se estabelecer qualquer doença metastática. Adrenalectomia está indicada na evidência de uma massa adrenal funcionante, ou na suspeita de

\section{atualização}

Franco Mantero

Nora Albiger
Department of Medical and Surgical Sciences, Endocrinology Unit, University of Padua, Padua, Italy.

Recebido em 11/06/04 Aceito em 14/06/04 
uma forma maligna. Nós recomendamos adrenalectomia para casos de hipercortisolismo sutil, especialmente em presença de hipertensão, obesidade, diabetes ou osteoporose, potencialmente agravados pelo excesso de glicocorticóides. Um acompanhamento rigoroso é necessário, particularmente no primeiro ano após o diagnóstico. (Arq Bras Endocrinol Metab 2004;48/5:583-591)

Descritores: Incidentaloma adrenal; Adenoma benigno; Carcinoma

A DRENAL INCIDENTALOMA is an adren mass discovered inadvertently during diagnostic tests or treatment for other clinical conditions unrelated to any suspicion of adrenal disease, though patients are often found retrospectively to have symptoms or signs of hormone oversecretion by the tumor. The definition of incidentaloma rules out patients undergoing imaging procedures for cancer staging and work-up. In the last 15-20 years, the widespread use of noninvasive imaging techniques has led to an increased detection of incidentalomas.

After the incidental diagnosis of an adrenal mass, it is important to establish whether the tumor is hormonally active. D ifferentiating between malignant and benign masses is also essential because metastases to adrenal glands are common. Adrenocortical carcinomas are rare, but they have a high mortality rate.

\section{CAUSes AND PREVALenCe}

In normal subjects, the prevalence of adrenal incidentalomas may depend on what imaging is done and why. In large series of patients screened using routine transabdominal ultrasonography (U S) during a general health examination, $0.1-0.5 \%$ had abnormal adrenal findings with a prevalence on the right side (1). The figure increases to $0.6-4.4 \%$ in series where computed tomography (CT) was performed and among patients with a previous diagnosis of cancer $(2,3)$. In cases evaluated by $\mathrm{CT}$, there was no apparent difference between sides. There may be bilateral masses in $10 \%$ of cases (4). In autopsy series, the prevalence of previously undiagnosed adrenal masses ranges between 1.4 and $8.7 \%(4,5)$.

The frequency of adrenal incidentaloma increases with age: it is uncommon under 30 years old and peaks between the fifth and seventh decades.

In more than 1000 cases evaluated by a multicenter study organized by the Adrenal Incidentaloma Study Group of the I talian Endocrinology Society (AI-
Table 1. Prevalence of causes of adrenal incidentalomas in Al-SIE series.

\begin{tabular}{lc}
\hline Type of tumor & AI-SIE \\
\hline Non-hypersecretory adrenal adenomas & 74.0 \\
Hypersecretory fumors: & \\
$\quad$ Cortisol-secreting adenomas & 9.2 \\
$\quad$ Pheochromocytomas & 4.2 \\
$\quad$ Aldosteronomas & 1.4 \\
Adrenal carcinomas & 4.0 \\
Other adrenal masses: & \\
$\quad$ Myelolipomas & 3.0 \\
$\quad$ Cysts & 1.9 \\
$\quad$ Ganglioneuromas & 1.5 \\
Metastases: & \\
$\quad$ Unselected patients & 0.7 \\
\hline
\end{tabular}

SIE), the patients' median age was 58 years and there was a significant female prevalence ( 584 women versus 420 men) (6). No gender differences were found in autopsy series, however.

Table 1 summarizes the prevalence of adrenal incidentalomas in the AI-SIE study and the histological diagnoses are illustrated in figure 1. Most adrenal incidentalomas are non-hypersecretory adenomas, but many patients with adrenal incidentalomas have revealed isolated or multiple mild abnormalities of the hypothalamic-pituitary-adrenal axis. M oreover, adrenal insufficiency following the surgical excision of "silent" adrenal adenomas has been described in 18$20 \%$ of cases, suggesting a condition of mild hypercortisolism. This situation of cortisol excess without the classic clinical signs may be a common finding in patients with incidental adrenal adenomas and it is termed subclinical Cushing's syndrome. The term subclinical autonomous glucocorticoid hypersecretion (SAGH ) has recently been proposed to define this situation (7). The prevalence of hypercortisolism in clinically inapparent adrenal masses reportedly ranges from 5 to $47 \%$ in various studies using different study protocols and diagnostic criteria (8-12). In our series of 208 adrenal incidentalomas, 29 patients met the cri-

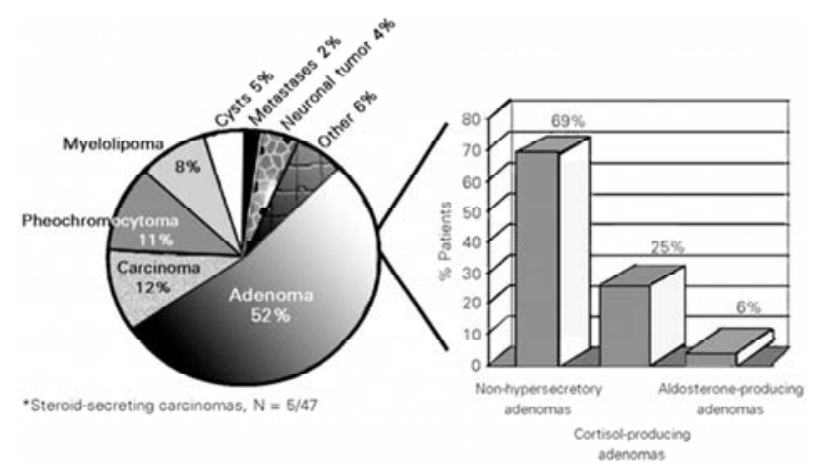

Figure 1. Histological diagnosis of 376 adrenal incidentalomas from the AL-SIE study.

Arq Bras Endocrinol Metab vol $48 n^{\circ} 5$ Outubro 2004 
teria for subclinical Cushing's syndrome, corresponding to a prevalence of $14 \%$

Pheochromocytoma is rare $(0.01-0.1 \%$ of hypertensive patients), and clinical manifestations vary. $\mathrm{H}$ ypertension is constant in only about half of the patients, paroxysmal in one third and absent in approximately one fifth. In the $\mathrm{M}$ ayo $\mathrm{Clinic}$ review of a 50-year autopsy series, pheochromocytoma was found in $0.13 \%$ of cases and the tumor had not been suspected in $75 \%$ of patients while alive, though it contributed to death in $55 \%$ of cases (13). So, a clinically silent pheochromocytoma is not so rare and its prevalence in patients with adrenal incidentalomas has been estimated in $1.5-13 \%(4)$. In the AI-SIE series, pheochromocytoma was the second most prevalent form of hyperfunctioning tumor, occurring in $4.2 \%$ of all masses. About half of the patients affected were normotensive, while the others had mild-to-moderate hypertension. $\mathrm{N}$ one of these patients had paroxysmal symptoms of adrenergic discharge. In the same series, a pheochromocytoma was confirmed by histology in $11 \%$ of patients who underwent adrenalectomy (6). A hormone evaluation to exclude pheochromocytoma should therefore be done routinely in patients with adrenal incidentalomas. The most frequent form of presentation is a sporadic pheochromocytoma, but up to $30 \%$ may be a component of hereditary syndromes. This percentage is now higher than was once reported (10\%), due to our increasing knowledge based on genetic studies. The hereditary syndromes include multiple endocrine neoplasia type 2 (MEN2), von $\mathrm{H}$ ippel-Lindau disease (VH L) and neurofibromatosis type 1 (N F-1), which are associated with an autosomal dominant inheritance pattern and variable penetrance.

The prevalence of primary aldosteronism is more frequent nowadays than previously reported. $\mathrm{U}$ sing the plasma aldosterone concentration/ plasma renin activity ratio (PAC/ PRA ratio) as a screening test for primary aldosteronism and studying patients with normokalemia have improved the recognition of this condition in the hypertensive population, though prevalence rates of $5-13 \%$ among all hypertensives have been described (14-16). An aldosteronoma is found in $1.6-3.3 \%$ of patients with adrenal incidentaloma $(6,17)$. The low prevalence found in the AI-SIE study (1.6\%) is probably explained by the exclusion of cases with severe hypertension and hypokalemia.

Adrenocortical carcinoma is rare, with an incidence ranging from 0.6 to 2 cases per million in the general population (18). The prevalence of primary adrenal carcinoma in clinically inapparent adrenal masses is related to the size of the mass. In tumors up to $4 \mathrm{~cm}$, adrenocortical adenomas account for $65 \%$ and carcinomas for $2 \%$. The larger the diameter of the mass, the greater the risk of it being malignant. M ost published series report a predominance of female patients (up to $90 \%$ in some series). In the AI-SIE series of adrenal incidentalomas, the relative frequency of malignancy was $4.6 \%$ (6).

Some incidental adrenal masses are infiltrative disease, fungal and tuberculosis infection, hemorrhage and lesions masquerading as adrenal but arising from adjacent organs (kidney, pancreas, gallbladder, spleen, lymph nodes). Primary adrenal lymphoma is uncommon, but it is important to recognize it because it is potentially curable.

\section{EVALUATION OF FUNCTIONAL STATUS}

Although most adrenal incidentalomas are non-hypersecretory adenomas, hormone evaluation is mandatory to identify cases of clinically unsuspected hormonesecreting adrenal tumors.

The NIH State-of-Science Conference panel (19) recommends the $1 \mathrm{mg}$ dexamethasone suppression test in all patients with incidentally detected adrenal masses. After taking $1 \mathrm{mg}$ dexamethasone overnight, a serum cortisol of less than $5 \mu \mathrm{g} / \mathrm{dl}$ ( $<$ $138 \mathrm{nmol} / \mathrm{l}$ ) at 8:00 a.m. is considered negative. We believe that cortisol insuppressibility would be better evaluated by lowering the cut-off to $3 \mu \mathrm{g} / \mathrm{dl}$. More recently, this cut-off level has been reduced to less than $1.8 \mathrm{ug} / \mathrm{dl}(50 \mathrm{nmol} / \mathrm{l})(20)$.

In the authors' series, the prevalence of cortisol excess in patients with adrenal incidentalomas was considerable. In the AI-SIE multicenter study, other abnormalities were seen in patients with cortisol excess

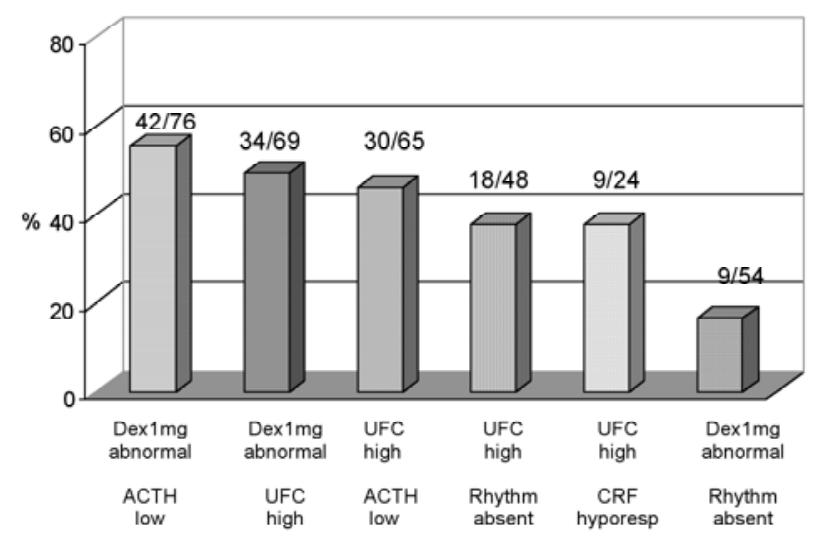

Figure 2. Abnormalities in patients with adrenal incidentalomas and subclinical Cushing's syndrome from the Al-SIE study. UFC: urinary free cortisol. 
and the most frequent combinations encountered are shown in figure 2.

Patients with adrenal incidentalomas may have a high prevalence of impaired glucose tolerance, previously undiagnosed diabetes mellitus, high triglyceride levels and arterial hypertension (21).

Fractionated urinary or plasma metanephrines (normetanephrine and metanephrine) should be assayed in all patients with adrenal incidentaloma, including normotensive patients (19). The sensitivity and specificity of 24-hour urine catecholamines are high, but this test is less sensitive than determining free metanephrines. Various medications may produce false-positive results when urinary metanephrines and catecholamines are measured (i.e. methyldopa, levodopa, labetalol, sotalol, tricyclic antidepressants, benzodiazepines, drugs containing catecholamines, amphetamines, withdrawal from clonidine and ethanol) and should be avoided, wherever possible, during evaluation for a suspect pheochromocytoma. Dynamic tests with clonidine suppression should be reserved for dubious cases. G lucagon testing may trigger a hypertensive crisis and is not recommended.

Chromogranin A is not specific for pheochromocytoma, since it may be elevated in other neuroendocrine tumors, but its evaluation may be useful. The level of chromogranin A correlates with tumor mass (7).

In patients with hypertension, serum potassium and a PAC/ PRA ratio should be determined to check for primary aldosteronism (19). A reference for the PAC/ PRA ratio should be ascertained at each center and the minimum PRA value included in the ratio should never be lower than the detection limit of the assay. The cut-off for the PAC/ PRA ratio suggesting the possibility of a primary aldosteronism should be calculated on the basis of normal reference ranges for PAC and PRA at each center. PAC and PRA should be expressed in $\mathrm{ng} / \mathrm{dl}$ and $\mathrm{ng} / \mathrm{ml} / \mathrm{h}$, respectively. A ratio higher than 20 with a PAC $\geq 15 \mathrm{ng} / \mathrm{dl}$ has been considered suspect for the diagnosis of primary aldosteronism $(22,23)$. In our experience, a PAC/ PRA ratio > 40 , with minimum PRA levels of $0.2 \mathrm{ng} / \mathrm{ml} / \mathrm{h}$, has $100 \%$ sensitivity and $84.4 \%$ specificity in screening patients with suspected primary aldosteronism. Several drugs can interfere with PAC and PRA measurements. It was classically recommended that patients undergoing this evaluation be taken off all antihypertension treatment for at least 2-3 weeks, but such a total washout could be unsafe in cases of severe hypertension, for whom calcium channel blockers and $\beta$-blockers seem to be a valid option. $\mathrm{O} n$ the other hand, some authors recommend doing the tests while patients are taking their antihypertension therapy, except for antialdosterone drugs and $\beta$-blockers (23). If they have hypokalemia, plasma potassium should be normalized and the ratio measured again 2 weeks later.

D ynamic tests are usually needed to confirm primary aldosteronism. Sodium-loading tests are usually employed, using fludrocortisone or saline infusion. Fludrocortisone is administered at a dose of $0.1 \mathrm{mg}$ four times daily for 4 days during dietary supplementation with $20-30 \mathrm{mmol}$ sodium 4 times a day, measuring aldosterone at the baseline and on days 3 and 4 . Primary aldosteronism is confirmed if upright PAC is $\geq 5 \mathrm{ng} / \mathrm{dl}$. O ral potassium supplementation may be needed (24). The saline infusion test is performed with an i.v. infusion of 2 liters of $0.9 \%$ isotonic saline over 4 hours while the patient is in a supine position. Primary aldosteronism is confirmed if PAC levels at the end of the test remain $>10 \mathrm{ng} / \mathrm{dl}$, and it is highly likely with levels $>7.5 \mathrm{ng} / \mathrm{dl}$, whereas it is excluded when PAC levels are $<5 \mathrm{ng} / \mathrm{dl}$. The captopril test has also been considered for screening or as a confirmatory test; various protocols have been proposed. Captopril can be administrated orally, $25-50 \mathrm{mg}$, measuring the PAC/ PRA ratio 2 hours later (or after 1 hour if $50 \mathrm{mg}$ are used) with the patient in the upright position. A ratio $>20$ is highly indicative, while a ratio $>30$ in a patient whose previous PAC/ PRA ratio was high confirms the diagnosis of primary aldosteronism $(25,26)$.

There is still controversy regarding the value of measuring dehydroepiandrosterone sulfate (DHEAS). Low DHEAS levels are frequently observed in subclinical C ushing's syndrome and adrenocortical adenomas, but the sensitivity and specificity of this parameter are poor ( $51 \%$ and $65 \%$ respectively) (27). Elevated DHEAS levels are frequently seen in patients with adrenocortical carcinoma (28), but other studies have found no convincing data that DHEAS is helpful in discriminating malignant from benign masses (27).

An exaggerated $17-\mathrm{OH}$-progesterone (17$\mathrm{OHP}$ ) response to $\mathrm{ACTH}$ stimulation is commonly observed in patients with adrenal incidentaloma, but its significance is still not clear. It has been suggested that an unrecognized defect of 21-hydroxylase could result in ACTH secretion and be a factor predisposing to adenoma formation. In 1992 Jaresh et al. (29) observed adrenal adenomas ( $>5 \mathrm{~mm}$ in diameter) by CT scan in $80 \%$ of patients with homozygous $21-0 \mathrm{H}$ deficiency and in $45 \%$ of heterozygous carriers - hence the suggestion that the ACTH test be used to reveal a congenital adrenal deficiency in patients with adrenal incidentalomas. In the AI-SIE study, an enhanced 17$\mathrm{OH} \mathrm{P}$ response was found in about half of the patients 
with cortical tumor, with no significant difference between unilateral and bilateral, or benign and malignant lesions. An enhanced 17-0 H P response was also observed in the majority of patients with subclinical Cushing's syndrome (68\%). M oreover, a normalization of this endocrine alteration was observed in most of the patients who had unilateral adrenalectomy (6). So, it is sometimes difficult to interpret the ACTH test and an exaggerated response of $17-\mathrm{OH} \mathrm{P}$ is not specific for 21-OH deficiency; it might merely be a sign of disturbed intratumoral steroidogenesis.

\section{EVALUATING MALIGNANCY}

Adrenocortical carcinoma can be functional or nonfunctional as regards hormone synthesis and clinical features. Using the clinical definition, functional tumors account for $26-94 \%$ of adrenocortical carcinomas $(30,31)$. H ypercortisolism or a combination of cortisol and androgen excess, are the most frequent presenting signs of functional tumors. M ost androgensecreting neoplasms are adrenocortical carcinomas rather than benign adenomas and they are more frequent in children (32). Estrogen-secreting tumors are rare and can cause feminization.

The lesion's size is an important parameter of malignancy: the larger the size, the greater the risk. The cut-off for suspected malignancy ranges between 3 and $6 \mathrm{~cm}$. Based on the receiver operating characteristic (ROC) curve for the diameter, as calculated from data in the AI-SIE study, $4 \mathrm{~cm}$ is considered a reasonable cut-off. Among the 47 cases of adrenal carcinoma found at surgery among the 387 patients considered in the AI-SIE study who had adrenalectomy, only 2 lesions were less than $4 \mathrm{~cm}$ in size. The mean diameter was $7.5 \mathrm{~cm}$, range $2.6-25 \mathrm{~cm}(6)$. M any types of adrenal lesion can present as large masses; so radiological features can facilitate the differential diagnosis $(33,34)$.

\section{IMAGING STUDIES}

Computed Tomography (CT) is an accurate tool for detecting adrenal masses. Adrenocortical adenomas usually appear on scans as small homogeneous round masses with smooth margins. Most lesions smaller than $4 \mathrm{~cm}$ appear to be benign (6). Calcification, necrosis and hemorrhage are uncommon in benign adenomas, but such lesions are not specific. Adenomas frequently contain a large amount of intracytoplasmatic lipid, which enables a quantitative evaluation by measuring the attenuation value of the lesions (expressed in $\mathrm{H}$ ounsfield units, $\mathrm{HU}$ ) (35). Adenomas usually have attenuation values below $18 \mathrm{H} \mathrm{U}$ on unenhanced $\mathrm{CT}$; when the lesion has an attenuation of less than $10 \mathrm{H} \mathrm{U}$, further work-up seems to be unnecessary, since it is probably a lipid-rich adrenal adenoma $(36,37)$. $M$ oreover, adenomas are generally characterized by rapid i.v. contrast washout. Lipid-poor adenomas have much the same enhancement and washout as lipid-rich adenomas, thus enabling their distinction from metastases $(37,38)$. A relative enhancement washout of more than $40-50 \%$ is highly suggestive of a benign mass (sensitivity $96 \%$, specificity $100 \%$ ), whereas lower relative washout percentages strongly suggest a metastasis.

By contrast, malignancies exhibit irregular margins and variable density, with strong enhancement and slow washout. Calcification, hemorrhage and necrosis are common (39). On magnetic resonance imaging (MRI), malignancies usually show high signal intensity on T2-weighted images, whereas most benign tumors have isointense or low signal intensity on both T1- and T2-weighted images. Approximately $30 \%$ of masses cannot be distinguished reliably on T2weighted images (40). Both CT and M RI are accurate in assessing tumor spread into tissues such as the liver, lymph nodes, lung and inferior vena cava. In our experience, CT and MRI were equally accurate in establishing the size of adrenal masses in a group of 67 patients, though the smallest lesions $(<3 \mathrm{~cm})$ were more accurately evaluated by M RI. The sensitivity of CT and M RI was similar in the differential diagnosis of adrenal tumors, but M RI imaging was more specific in confirming a clinical suspicion of pheochromocytoma and carcinoma. M ost (65\%) of the adenomas evaluated with CT, MRI or both, were homogeneous, while both methods showed carcinomas as being nonhomogeneous. $C$ arcinomas were variably hyperintense on T2-weighted MR images and the margins were irregular in all cases. U nfortunately, this was often also true on CT and MRI scans of pheochromocytomas (in $62 \%$ and $83 \%$ of cases, respectively). For all tumors a positive correlation was found between the size detected on CT or M RI and after surgery $(r=0.92 ; p<0.0001)$.

Pheochromocytoma is typically isointense with respect to the liver on T1-weighted images and hyperintense on T2-weighted images, whereas adrenal carcinomas and metastases may have a similar T2-weighted hyperintensity. In our experience, all pheochromocytomas revealed $\mathrm{T} 2$ hyperintensity.

An adrenal incidentaloma may be a metastasis from other tumors (lung, breast, colon, kidney, melanoma or lymphoma). Adrenal metastases have 
been documented at autopsy in as many as $38 \%$ of cancer patients. M orphological CT images are non-specific. The size of the mass varies, but it is less well defined than adenoma. H emorrhage or central necrosis may produce irregular cystic areas. Several studies have demonstrated a significantly slower contrast material washout in metastases than in adenomas $(41,42)$. In the presence of a mass with a high attenuating value ( $>$ $20 \mathrm{H} \mathrm{U}$ ) and when a metastasis is suspected, ultrasound or CT-guided fine-needle aspiration is a useful diagnostic tool for evaluating adrenal lesions with a sensitivity of $81-100 \%$, a specificity of $83-100 \%$ and an accuracy of $91 \%(43,44)$. Pheochromocytoma should always be ruled out before this procedure is attempted to avoid the risk of a hypertensive crisis (19).

Adrenocortical scintigraphy using 131|-6biodomethyl-19-norcholesterol (N P59) or ${ }^{75} \mathrm{Se}-$ methylnorcholesterol assures not only the anatomical localization of the adrenal glands but also their in vivo functional characterization (45). A discordant scintigraphic pattern demonstrating little or no radiocholesterol uptake by the affected adrenal gland is compatible with malignancies (primary or secondary) or destructive adrenal lesions. In our series, 4 out of 5 malignant tumors showed this pattern. It has been suggested that a concordant scintigraphic pattern, defined as a unilateral adrenal visualization or increased radiotracer uptake with virtually no contralateral gland, is typical of benign cortical adenomas or nodular hyperplasia. In our series, $54 \%$ of benign lesions showed a concordant uptake, while there was only a partially increased uptake on the side of adenoma in another $28 \%$ of cases. Adrenal masses less than $2 \mathrm{~cm}$ in size may show a normal pattern, bilaterally demonstrating a symmetrical uptake, representing the resolution limit of this technique.

Scintigraphy with ${ }^{131}$ | or 123 |-meta-iodobenzylguanidine (MIBG) or 111| n-octreotide should be performed to evaluate a suspected pheochromocytoma (46).

A more promising technique is positron emission tomography with ${ }^{18} \mathrm{~F}$-fluorodeoxyglucose (FD GPET). M ost malignant tumors show an enhanced glycolytic metabolism with an increased deoxyglucose uptake (47).

\section{MANAGEMENT}

After the incidental discovery of an adrenal mass, two major issues should be addressed in formulating a treatment plan: 1) is the tumor hormonally active even

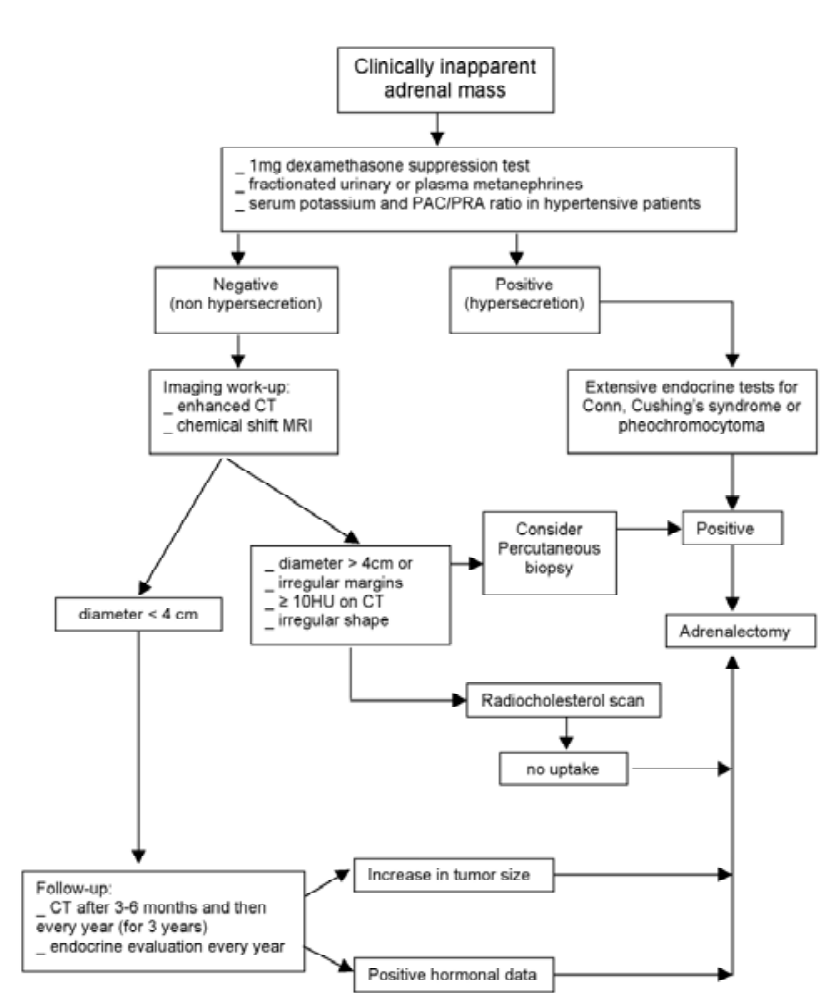

Figure 3. Approach to the management of adrenal incidentaloma. PAC: plasma aldosterone concentration, PRA: plasma renin activity.

in the absence of a classic clinical presentation? and 2) is there any chance of the mass being malignant?

If history and physical examination in a patient with a unilateral form suggest a clinical endocrine syndrome and this is biochemically confirmed, adrenalectomy is considered the treatment of choice (figure 3 ). N owadays, laparoscopic adrenalectomy is preferred by most endocrine surgeons. O pen adrenalectomy is the exception, but it may be necessary to convert to an open procedure during laparoscopy due to finding a large, potentially malignant mass. L aparoscopic resection of benign adrenal masses is a safe and effective method involving a shorter hospital stay (48). The needle endoscopic approach, the remote-controlled robotic surgical system and gasless laparoscopic adrenalectomy have also been used. Conservative techniques such as autotransplantation of adrenocortical tissue or subtotal adrenalectomy have been proposed in some particular cases where bilateral adrenalectomy was indicated. Experience with autotransplantation has been disappointing in most studies (49). A variable rate of recurrence has been reported after subtotal adrenalectomy. Recently, unilateral subtotal with contralateral total adrenalectomy has been recommended in patients with bilateral familial pheochromocytoma. 
In cases of contraindications for surgery or unresectable lesions, medical treatment may be an option. We advocate preoperative medical treatment with an alpha-1 adrenergic antagonist (e.g. prazosin, doxazosin) in patients with incidental pheochromocytoma, even if they are normotensive. Such treatment enables the expansion of the vascular bed and plasma volume and reduces the amount of fluid needed to maintain the blood pressure when the tumor is removed.

In the absence of clinical syndromes, treatment decisions may be more difficult. An exception is the "silent" pheochromocytoma, which carries a risk of hypertensive crisis and should prompt adrenalectomy. Although the natural history of subclinical Cushing's syndrome and its morbidity are unclear, we advocate adrenalectomy for patients with this condition, especially in the presence of hypertension, obesity, diabetes or osteoporosis potentially aggravated by glucocorticoid excess. Since the hypothalamus-pituitary-adrenal axis and the contralateral adrenal gland may be suppressed by prolonged cortisol secretion, these patients require glucocorticoid therapy both during and after surgery. While adrenalectomy has been found to correct biochemical abnormalities, its effect on long-term outcome and quality of life is unknown, so careful observation has also been suggested as a treatment option (19).

As mentioned above, the risk of malignancy increases with the size of the mass. Homogeneous lesions with regular margins less than $4 \mathrm{~cm}$ in size are unlikely to have malignant potential and are generally not resected. According to the $\mathrm{N} \mathrm{H} \mathrm{I} \mathrm{State-of-Science}$ Conference panel (19), the general recommendation is to excise lesions larger than $6 \mathrm{~cm}$. For lesions between 4 and $6 \mathrm{~cm}$, either closer follow-up or adrenalectomy (an option preferred by our group on the strength of our personal experience) are both considered reasonable. In cases of rapid growth, low lipid content and other features described earlier suggestive of adrenal carcinoma, surgery is the treatment of choice. Finally, adrenalectomy does not seem to be beneficial in the case of metastases from a known or unknown primary neoplasm (19).

Long-term follow-up studies suggest that most adrenal lesions remain stable, whereas 5-25\%grow and a small percentage may shrink. Follow-up in the first years is mandatory. We advocate a CT/ M RI scan at 3to 6-month intervals in the first year after detecting the adrenal incidentaloma. A clinical (hormonal and radiological) evaluation should be performed after 1 year, then every 1-2 years for a time that will be better defined in the light of data emerging from the longterm follow-up of large series (50).

Preliminary data have demonstrated that malignancy is an extremely rare event, even among tumors that slowly increase in size and exceed the $4 \mathrm{~cm}$ cut-off. The prevalence of hypothalamus-pituitary axis abnormalities may also increase, especially with tumors larger than $3 \mathrm{~cm}$ in diameter (51), but evolution of overt Cushing's syndrome has also seldom been observed.

\section{REFERENCES}

1. Masumori N, Adachi H, Hokfelt B. Detection of adrenal and retroperitoneal masses in a general health examination system. Urology 1968;52:572-6.

2. Glazer HZ, Weyman PJ, Sagel SS, Levitt RG, McClennan BL. Nonfunctioning adrenal masses: incidental discovery on computed tomography. Am J Roentgenol $1982 ; 139: 81-5$

3. Caplan RH, Strutt PJ, Wickus GC. Subclinical hormone secretion by incidentally discovered adrenal masses. Arch Surg 1994;129:291-6.

4. Kloos RT, Gross MD, Francis IR, Korobkin M, Shapiro B. Incidentally discovered adrenal masses. Endocr Rev $1995 ; 16: 460-84$.

5. Hedeland $\mathrm{H}$, Ostberg $\mathrm{G}$, Hokfelt $\mathrm{B}$. On the prevalence of adrenocortical adenomas in an autopsy material in relation to hypertension and diabetes. Acta Med Scand 1968;184:211-4.

6. Mantero F, Terzolo M, Arnaldi G, Osella G, Masini AM, Ali $A$, et al. On behalf of the Study Group on Adrenal Tumors of the Italian Society of Endocrinology. J Clin Endocrinol Metab 2000;85:637-44.

7. Mansmann $G$, Lau J, Balk E, Rothberg M, Miyachi $Y$, Bornstein SR. The clinically inapparent adrenal mass: Update in diagnosis and management. Endocr Rev 2004;25:309-40.

8. Rossi R, Tauchmanova L, Luciano A, DI Martino M, Battista C, Del Viscovo L, et al. Subclinical Cushing's syndrome in patients with adrenal incidentaloma: clinical and biochemical features. J Clin Endocrinol Metab 2000;85:1440-8.

9. Reincke M, Nieke J, Krestin GP, Saeger W, Allolio B, Winkelmann W. Preclinical Cushing's syndrome in adrenal "incidentalomas": comparison with adrenal Cushing's syndrome. J Clin Endocrinol Metab 1992;75:826-32.

10. Terzolo M, Osella G, Ali A, Borretta G, Cesario F, Paccotti $P$, et al. Subclinical Cushing's syndrome in adrenal incidentaloma. Clin Endocrinol (Oxf) 1998;48:89-97.

11. Valli N, Catargi B, Ronci N, Vergnot V, Leccia F, Ferriere $\mathrm{JM}$, et al. Biochemical screening for subclinical cortisolsecreting adenomas amongst adrenal incidentalomas. Eur J Endocrinol 2001;144:401-8.

12. Emral R, Uysal AR, Asik M, Gullu S, Corapcioglu D, Tonyukuk V, et al. Prevalence of subclinical Cushing's syndrome in 70 patients with adrenal incidentaloma: clinical, biochemical and surgical outcomes. Endocr J 2003;50:399-408. 
13. Sutton MG, Sheps SG, Lie JT. Prevalence of clinically unsuspected pheochromocytoma: a review of a 50years autopsy series. Mayo Clin Proc 1981;56:354-60.

14. Rossi E, Regolisti G, Negro A, Sani C, Davoli S, Perazzoli F. High prevalence of primary aldosteronism using postcaptopril plasma aldosterone to renin ratio as a screening test among Italian hypertensives. Am J Hypertension 2002; 15:896-902.

15. Gordon RD, Stowasser M, Tunny TJ, Klemm SA, Rutherford JC. High incidence of primary aldosteronism in 199 patients referred with hypertension. Clin Exp Pharmacol 1994;21:315-8.

16. Fardella C, Mosso L, Gomez-Sanchez C, Cortez P, Soto J, Gomez L, et al. Primary hyperaldosteronism in essential hypertensives: prevalence, biochemical profile and molecular biology. J Clin Endocrinol Metab 2000;85: 1863-7.

17. Bernini G, Moretti A, Argenio G, Salvetti A. Primary aldosteronism in normokalemic patients with adrenal incidentalomas. Eur J Endocrinol 2002; 146:523-9.

18. Latronico AC, Crousos GP. Extensive personal experience: adrenocortical tumors. J Clin Endocrinol 1997;82:1317-24.

19. Grumbach MM, Biller BMK, Braunstein GD, Campbell KK, Carney A, Godley PA, et al. Management of the clinically inapparent adrenal mass ("Incidentaloma"). Ann Intern Med 2003; 138:424-9.

20. Arnaldi $G$, Angeli A, Atkinson AB, Bertagna $X$, Cavagnini $F$, Chrousos GP, et al. Diagnosis and complications of Cushing's syndrome: a consensus statement. J Clin Endocrinol Metab 2003;88:5593-602.

21. Terzolo M, Pia A, Ali A, Osella G, Reimondo G, Bovio S, et al. Adrenal incidentaloma: a new cause of the metabolic syndrome? J Clin Endocrinol Metab 2002;87:9981003.

22. Litchfield WR, Dluhy RG. Primary aldosteronism. Endocrinol Metab Clin North Am 1995;24:593-612.

23. Young Jr WF. Minireview: Primary aldosteronism-changing concepts in diagnosis and treatment. J Clin Endocrinol Metab 2003;144:2208-13.

24. Holland $\mathrm{OB}$, Brown $\mathrm{H}$, Kuhnert L, Fairchild $\mathrm{C}$, Risk M, Gomez-Sanchez CE. Further evaluation of saline infusion for the diagnosis of primary aldosteronism. Hypertension 1984;6:717-23.

25. Mantero F, Fallo F, Opocher G, Armanin D, Boscaro M, Scaroni $C$. Effect on angiotensin II and convertineenzyme inhibitor (captopril) on blood pressure, PRA and aldosterone in primary aldosteronism. Clin Sci (Lond) 1981;61:289S-293S.

26. Agharazii M, Douville P, Grose JH, Lebel M. Captopril suppression versus salt loading in confirming primary aldosteronism. Hypertension 2001;37:1440-3.

27. Bencsik Z, Szabolks I, Kovacks Z, Ferencz A, Voros A, Kaszas I, et al. Low dehydroepiandrosterone sulfate (DHEAS) level is not a good predictor of hormonal activity in nonselected patients with incidentally detected adrenal tumors. J Clin Endocrinol Metab 1996;81:17269.

28. Terzolo M, Ali A, Osella G, Reimondo G, Pia A, Peretti P, et al. The value of dehydroepiandrosterone sulfate measurement in the differentiation between benign and malignant adrenal masses. Eur $\mathbf{J}$ Endocrinol 2000;142:611-7.

29. Jaresch S, Kornely E, Kley HK, Schlaghecke R. Adrenal incidentaloma and patients with homozygous or heterozygous congenital adrenal hyperplasia. J Clin Endocrinol Metab 1992;74:685-9.

30. Wooten MD, King DK. Adrenal cortical carcinoma. Epidemiology and treatment with mitotane and a review of literature. Cancer 1993;72:3145-55.

31. Wajchenberg BL, Albergaria Pereira MA, Medonça BB, Latronico AC, Campos Carneiro P. Alves VA, et al. Adrenocortical carcinoma: clinical and laboratory observations. Cancer 2000;88:711-36.

32. Patil KK, Ransley PG, McCullagh M, Malone M, Spitz L. Functioning adrenocortical neoplasms in children. BJU Int 2002;89:562-5.

33. Peppercorn PD, Grossman AB, Reznek RH. Imaging of incidentally discovered adrenal masses. Clin Endocrinol 1998;48:379-88.

34. Pender SM, Boland GW, Lee MJ. The incidentally nonhyperfunctioning adrenal mass: an imaging algorithm for characterization. Clin Endocrinol 1998;53:796-804.

35. Korobkin M, Brodeur FJ, Yutzy GG, Francis IR, Quint LE, Dunnick NR, et al. Differentiation of adrenal adenomas from nonadenomas using CT attenuation values. Am J Roentgenol 1996;166:531-6.

36. Szolar DH, Kammerhuber F. Quantitative CT evaluation of adrenal gland masses: a step forward in the differentiation between adenomas and nonadenomas? Radiology 1997;202:517-21.

37. Caoili EM, Korobkin M, Francis IR, Cohan RH, Platt JF, Dunnick NR, et al. Adrenal masses: characterization with combined unenhanced and delayed enhanced CT. Radiology 2002;222:629-33.

38. Kebapci M, Kaya T, Gurbuz E, Adapinar B, Kebapci N, Demirustu $C$. Differentiation of adrenal adenomas (lipid rich and lipid poor) from nonadenomas by use of washout characteristics on delayed enhanced CT. Abdom Imaging 2003;28:709-15.

39. Fishman EK, Deutch BM, Hartman DS, Goldman SM, Zerhoumi EA, Siegelman SS. Primary adrenocortical carcinoma: CT evaluation with clinical correlation. Am J Roentgenol 1987; 148:531-5.

40. Glazer GM, Woolsey EJ, Borrello J, Francis IR, Aisen AM, Bookstein $F$, et al. Adrenal tissue characteristics using MR imaging. Radiology 1986;158:73-9.

41. Korobkin M, Brodeur FJ, Francis JR, Quint LE, Dunnick NR, Goodsitt M. Delayed enhanced CT for differentiation of benign from malignant adrenal masses. Radiology 1996;200:737-42.

42. Szolar DH, Kammerhuber FH. Adrenal adenomas and non adenomas: assessment of washout at delayed contrast-enhanced CT. Radiology 1998;207:369-75.

43. Welch TJ, Sheedy $2^{\text {nd }}$ PF, Stephens DH, Johnson CM, Swensen SJ. Percutaneous adrenal biopsy: review of a 10-year experience. Radiology 1994;193:341-4.

44. Saeger W, Fassnacht M, Chita R, Prager G, Nies C, 
Lorenz $\mathrm{K}$, et al. High diagnostic accuracy of adrenal core biopsy: results of the German and Austrian adrenal network multicenter trial in 220 consecutive patients. Hum Pathol 2003;34:180-6.

45. Gross MD, Rubello D, Shapiro B. Is there a future for adrenal scintigraphy? Nucl Med Commun 2002;23:197-202.

46. Shapiro B, Copp JE, Sisson JC, Eyre PL, Wallis J, Beirwaltes WH. lodine-131- metaiodobenzylguanidine for the locating of suspected pheochromocytoma: experience in 400 cases. J Nucl Med 1985;26:576-85.

47. Yun M, Kim W, Alnafisi N, Lacorte L, Jang S, Alavi A. 18FFDG-PET in characterizing adrenal lesions detected on CT or MRI. J Nucl Med 2001;42:1795-9.

48. Jaroszewski DE, Tessier DJ, Schlinkert RT, Grant CS, Thompson GB, van Heerden JA, et al. Laparoscopic adrenalectomy for pheochromocytoma. Mayo Clin Proc 2003;78:1501-4.

49. Okamoto T, Obara T, Ito Y, Yamashita t, Kanbe M, lihara $\mathrm{M}$, et al. Bilateral adrenalectomy with autotransplantation of adrenocortical tissue or unilateral adrenalectomy: Treatment options for pheochromocytomas in multiple endocrine neoplasia type $2 \mathrm{~A}$. Endocr J 199; 43:169-75.

50. Arnaldi G, Masini G, Giacchetti A; Taccaliti A, Faloia E, Mantero F. Adrenal incidentaloma. Braz J Med Biol Res 2000;33:1 177-89.

51. Barzon L, Fallo F, Sonino N, Boscaro M. Development of overt Cushing's syndrome in patients with adrenal incidentaloma. Eur J Endocrinol 2002;146:61-6.

\section{Endereço para correspondência:}

Franco Mantero

Department of Medical and Surgical Sciences University of Padova

via Ospedale, 105

35128 Padova, Italy

Fax: 039-049657391

e-mail: franco.mantero@unipd.it 